\title{
Prevalence of Addiction and Smoking and Their Relationship With Blood Parameters Among Drivers in Zahedan
}

\author{
Alireza Ansari-Moghaddam, ${ }^{1}$ Hossein Ansari, ${ }^{1,}{ }^{,}$Mahdi Mohammadi, ${ }^{1}$ Seyed Mehdi Tabatabaei, \\ Mohammadreza Pishevare-Mofrad, ${ }^{1}$ and Mahmodreza Miri-Bonjar ${ }^{1}$ \\ ${ }^{1}$ Health Promotion Research Center, Zahedan University of Medical Sciences, Zahedan, IR Iran \\ "Corresponding author: Hossein Ansari, Health Promotion Research Center, Zahedan University of Medical Sciences, Zahedan, IR Iran. Tel: +98-9126309480, Fax: \\ +98-5433425375, E-mail: ansarih88@gmail.com
}

Received 2015 February 21; Revised 2015 May 23; Accepted 2015 June 01.

\begin{abstract}
Background: Although smoking and drug use are the major causes of accidents and death of drivers, few studies have been conducted on the prevalence of smoking and its associated factors in this occupational group.

objectives: The current study aimed to investigate the prevalence of smoking and its relationship with blood parameters among drivers in Zahedan city, Iran.

Patients and Methods: In this study, 1836 inner and intercity drivers were investigated in 2013 in terms of smoking and drug use and blood parameters. Data were obtained through in-depth interviews and necessary examinations and tests, and were analyzed by Stata.12 software using Chi-square, independent t-test, and multiple regression analysis at significance level of 0.05.

Results: Generally, four drivers were addicted to drugs and smoked as well. Two-hundred and eighty eight drivers (15.8\%) reported daily smoking. Variables of age, education, and type of vehicle showed a significant relationship with smoking. No significant difference was found in blood parameters between the smokers and non-smokers.

Conclusions: Despite relatively high prevalence of smoking than drug use in Zahedan drivers, there are few reports of these behaviors. Laboratory tests cannot suitably measure substance use due to their interference with other substances. Considering adverse effects of smoking on health and driving, it is necessary to train drivers to reduce or stop smoking during driving.
\end{abstract}

Keywords: Smoking, Beaviors-Addictive, Drivers

\section{Background}

In terms of traffic accident mortality, Iran is among the world's leading countries (1). According to the world health organization (WHO), road crashes are the ninth most frequent cause of death, especially in countries with low or average income (2). Studies show that people with anxiety are predisposed to risky behaviors such as smoking. Moreover, those with high-risk behaviors are more likely to have accidents (3).

Most of the traffic accidents relate to driving skills, which are in turn closely related to physical capabilities (4). Many studies show that accidents and their severity are associated with age, sleepiness, drug use and smoking (511). Some studies attribute accidents causing injury specifically to behavior changes in drivers following smoking and history of smoking (10-12). Some studies have reported the prevalence of smoking by drivers $6 \%$ to $49.6 \%$, and mostly in male drivers (10-13). These studies considered smoking during driving inappropriate and dangerous, and a major cause of drivers' death.

Various studies show that working shift can be associated with level of blood parameters and metabolic syndromes, and due to irregular working hours, these drivers may be considered as the target group $(14,15)$. Smoking and type of work in drivers may have synergistic effects in causing inappropriate blood parameters and subsequent disorders, and investigating this problem illustrates the importance of the relationship between smoking and blood parameters.

Some of the factors affecting drivers' health to drive, especially driving heavy vehicles, include drugs, alcohol, and other illegal substances (16). Since it is difficult to collect such data, and a driver may not easily and correctly answer questions about using such drugs, studying the prevalence of smoking may somewhat indicate the use of other substances. Smoking partly shows driver's mental stability and affects his driving $(10,11)$. In Iran, opiate use is more important than using other drugs (16).

Considering the importance of road accidents, drivers' 
health, and its relationship with driving accidents, it is essential to study high-risk behaviors such as smoking and related factors. It is also important to study the relationship between blood parameters and smoking to persuade drivers to quit through educational programs.

\section{Objectives}

The current study aimed to investigate the prevalence of smoking and addiction and their related factors, and the relationship between smoking and blood parameters among drivers in Zahedan. The results may be used to design better educational programs and further planning to quit or reduce cigarette use, and ultimately prevent accidents.

\section{Patients and Methods}

In the current study, 1836 inner and intercity drivers in Zahedan were investigated in 2013. Subjects included drivers with class A and B licenses who had to attend a clinic namely Hannaneh for the annual examination. Data were obtained through in-depth interviews and examinations and tests, and recorded in information forms, which included two parts of demographic details and smoking history and blood test results. To ensure true answers, explanations about study objectives and assurances about confidentiality of data were given, and participants entered the study with informed consents. Blood test was performed to check drivers' reliability toward drug use and addiction. Data were analyzed by Stata version12 software using Chi-square, independent t-test, and multiple regression analysis at significance level of 0.05 . T-test was used to compare means of quantitative variables between smokers and non-smokers. The association between two qualitative variables was examined by Chi-square test in a univariate model. Finally, multiple regression analysis was used to find out the association between variables after controlling the confounders.

\section{Results}

A total of 1836 inner and intercity Zahedan drivers were studied. Three hundred and eighty five of them (21\%) were younger than 30 . Forty-seven (2.6\%) were illiterate, and only $42(2.3 \%)$ had university education, 115 (6.3\%) were single, and 632 (34.4\%) had class A driving licenses.

Generally, four drivers were addicted to opiates and smoked. Two-hundred and eighty eight drivers (15.8\%) reported daily smoking (CI 95\%: 8.8 - 20.3). Table 1 presents distribution of smoking according to demographic variables. In a univariate analysis, Chi-square test showed a significant relationship between age, education, type of vehicle and smoking.

Variables of age, type of driving license, and type of vehicle remained in the final model based on HosmerLemshaw in both univariate analyses using Chi-square and multiple analyses using logistic regression, and showed a significant relationship with smoking (Table 2). HosmerLemshaw showed good fitness in the final model $(\mathrm{P}=0.43)$.

Furthermore, the relationship between some blood parameters and smoking was examined. Independent $\mathrm{t}$ test showed significantly greater means of fasting blood sugar $(\mathrm{P}=0.044)$ and cholesterol $(\mathrm{P}=0.043)$ in smokers compared to non-smokers. In other blood parameters, no significant difference was found between smokers and non-smokers $(\mathrm{P}>\mathrm{0.05})$. Moreover, non-smoking drivers showed more favorable triglyceride levels than smoking drivers. Table 3 shows mean and standard deviation of blood test results in smoking and non-smoking drivers, at a significant level.

Variables of age (over 40 years) and smoking synergistically affected blood parameters; the means of fasting glucose in smokers over 40 and under 40 years were $122.1 \pm$ 37.3 and $92.5 \pm 31.4 \mathrm{mg} / \mathrm{dL}$, respectively $(\mathrm{P}=0.001)$; means of cholesterol in these groups were $218.1 \pm 47.2$ and $192.5 \pm$ $441.4 \mathrm{mg} / \mathrm{dL}$, respectively $(\mathrm{P}=0.001)$; and means of triglyceride were $170 \pm 33.3$ and $155.5 \pm 41.6 \mathrm{mg} / \mathrm{dL}$, respectively $(\mathrm{P}=0.001)$. Variables of older age and smoking showed no synergistic effect on increasing the level of blood parameters.

Examining the trend of some blood parameters means in Zahedan drivers from 2005 to 2009 showed no tangible trend in any of the blood parameters (Figure 1).

\section{Discussion}

Despite the use of laboratory techniques, drug use was found to be very low among drivers. A study in Iran reported the prevalence of drug use among drivers who had the history of car accident more than 50\% $(5,17)$. Using morphine-check test, Motevalian et al. (16) reported the prevalence of opiate use in heavy vehicle drivers close to $15 \%$, and the prevalence of smoking $52 \%$. In the current study, given low levels of drug use among drivers (even according to laboratory tests), it seems that laboratory tests cannot be considered the golden standard to detect drug use because some people use compounds that may react with opiates in blood, rendering them undetectable, and recently it is commonplace among drivers. Besides, the above studies were conducted several years ago, when use of compounds that make opiates undetectable in blood 
Table 1. Frequency Distribution of Drivers Smoking According to Demographic Data ${ }^{\mathrm{a}}$

\begin{tabular}{|c|c|c|c|}
\hline Smoking/Independent Variables & Yes & No & P Value \\
\hline Age, $y$ & & & 0.0001 \\
\hline Under 29 & $32(8.3)$ & $353(91.7)$ & \\
\hline $30-39$ & $88(13.8)$ & $550(86.1)$ & \\
\hline $40-49$ & $105(23.2)$ & $348(76.8)$ & \\
\hline Over 50 & $57(21.3)$ & $210(78.7)$ & \\
\hline Education & & & 0.0001 \\
\hline Illiterate & $13(27.7)$ & $34(72.3)$ & \\
\hline Junior high school & $215(17.7)$ & $996(82.3)$ & \\
\hline Senior high school university & $53(10)$ & $476(90)$ & \\
\hline Type of vehicle & $6(14.3)$ & $36(85.7)$ & \\
\hline Taxi & $43(25.9)$ & $123(74.1)$ & 0.0001 \\
\hline Non-taxi & $245(14.7)$ & $1425(85.3)$ & \\
\hline Type of license & & & 0.14 \\
\hline Class A & $178(14.8)$ & $1026(75.2)$ & \\
\hline Class B & $110(17.4)$ & $522(82.6)$ & \\
\hline Marital status & & & 0.06 \\
\hline Single & $11(9.6)$ & $104(90.4)$ & \\
\hline Married & $277(16.1)$ & $1444(83.9)$ & \\
\hline Total & $290(15.8)$ & $1546(84.2)$ & \\
\hline
\end{tabular}

${ }^{\mathrm{a}}$ Values are expressed as No. (\%).

Table 2. Logistic Regression Coefficients in Related Factors to Smoking Among Drivers

\begin{tabular}{|c|c|c|c|c|c|c|}
\hline \multirow[t]{2}{*}{ Dependent Variables } & \multirow[t]{2}{*}{$\beta$} & \multirow[t]{2}{*}{ S.E } & \multirow[t]{2}{*}{ PValue } & \multirow[t]{2}{*}{$\operatorname{Exp}(\beta)$} & \multicolumn{2}{|c|}{ 95.0\% C.I. for $\operatorname{Exp}(B)$} \\
\hline & & & & & Lower & Upper \\
\hline \multicolumn{7}{|l|}{ Age, $y$} \\
\hline Under 29 & & & & 1 & & \\
\hline $30-39$ & 1.001 & 0.271 & 0.000 & 2.721 & 1.598 & 4.633 \\
\hline $40-49$ & 0.455 & 0.206 & 0.027 & 1.577 & 1.054 & 2.360 \\
\hline Over 50 & -0.181 & 0.199 & 0.363 & 0.834 & 0.565 & 1.233 \\
\hline \multicolumn{7}{|l|}{ Type of license } \\
\hline Class A & & & & 1 & & \\
\hline Class B & 0.301 & 0.147 & 0.041 & 1.351 & 1.012 & 1.802 \\
\hline \multicolumn{7}{|l|}{ Type of vehicle } \\
\hline Non-taxi & -0.684 & 0.206 & 0.001 & 0.505 & 0.337 & 0.756 \\
\hline
\end{tabular}

Abbreviations: $\beta$, Regression coefficient; S.E, standard error of $\beta$; OR, odds ratio.

was not so common among drivers. Furthermore, high frequency of drug use among the smoking drivers and high frequency of smoking drivers $(5,11,12,16)$ also show why drug use was reported so low in this study. 


\begin{tabular}{|c|c|c|c|c|}
\hline Blood & Parameters/Smoking & $\mathbf{N}$ & Mean \pm SD & P Value \\
\hline RBC & & & & 0.138 \\
\hline & Yes & 286 & $5.96 \pm 6.7$ & \\
\hline & No & 1535 & $5.63 \pm 2.3$ & \\
\hline MCV & & & & 0.16 \\
\hline & Yes & 287 & $83.25 \pm 15.4$ & \\
\hline & No & 1531 & $81.98 \pm 14.1$ & \\
\hline MCH & & & & 0.0 .6 \\
\hline & Yes & 286 & $29.85 \pm 16.3$ & \\
\hline & No & 1536 & $29.41 \pm 17.1$ & \\
\hline MCHC & & & & 0.42 \\
\hline & Yes & 286 & $33.05 \pm 2.9$ & \\
\hline & No & 1536 & $32.86 \pm 3.8$ & \\
\hline FBS & & & & 0.044 \\
\hline & Yes & 286 & $117.10 \pm 36.0$ & \\
\hline & No & 1534 & $96.04 \pm 35.2$ & \\
\hline CHOL & & & & 0.043 \\
\hline & Yes & 287 & $207.65 \pm 46.2$ & \\
\hline & No & 1533 & $198.47 \pm 58.9$ & \\
\hline TG & & & & 0.4 \\
\hline & Yes & 285 & $162.57 \pm 31.3$ & \\
\hline & No & 1534 & $157.78 \pm 29.5$ & \\
\hline
\end{tabular}

Nevertheless, frequency of smoking was greater than drug use in Zahedan drivers, which was relatively low, compared to previous studies in Iran $(5,16)$ and worldwide (1113). A study conducted in Iran (18) reported the prevalence of smoking in drivers $25 \%$. Thus, it seems that self-report by drivers cannot be considered a valid and reliable method. According to the history of smoking in drivers worldwide, the actual rate of smoking must surely be higher than reported by drivers. Therefore, measurement according to self-report will lead to low estimates. Given the relationship between smoking, driving, and accidents $(10,11)$, and the effect of smoking on individual's tendency to use opiates that may deter smoking quit attempts (16-18), it seems that smoking not only does not make drivers more alert, but also has direct and indirect effects on their health, and affects the rates of accidents and accident-related mortality. The present study results agree with those of the study in South Khorasan, Iran (19) in terms of prevalence of smoking, which may be due to cultural similarities of drivers, or measuring technique, self-report.

Previous studies show that smoking is more preva- lent among drivers compared to other jobs. Considering peer effect in smoking (20), one of the reasons for high prevalence of smoking in drivers may be their smoking colleagues. Educational programs and advice by the police may be much more effective in reducing smoking in drivers than other institutions.

The present study showed that smoking was significantly related to driver's age, type of license, and type of vehicle. It was found that odds of smoking increased with aging. Yet, smoking drastically reduces with age over 50 years. This may be due to the fact that experienced drivers were not smokers at first, while young drivers tend to smoke more, due to increased number of young smokers in recent years.

The study also demonstrated (other variables being equal) greater prevalence of smoking in class B licensed drivers than in class $\mathrm{A}$, which could be due to the younger age and greater tendency to smoking in class B drivers. Therefore, providing educational programs during drivers training and explaining the relationship between smoking, health and accidents may be used as a strategy to re- 


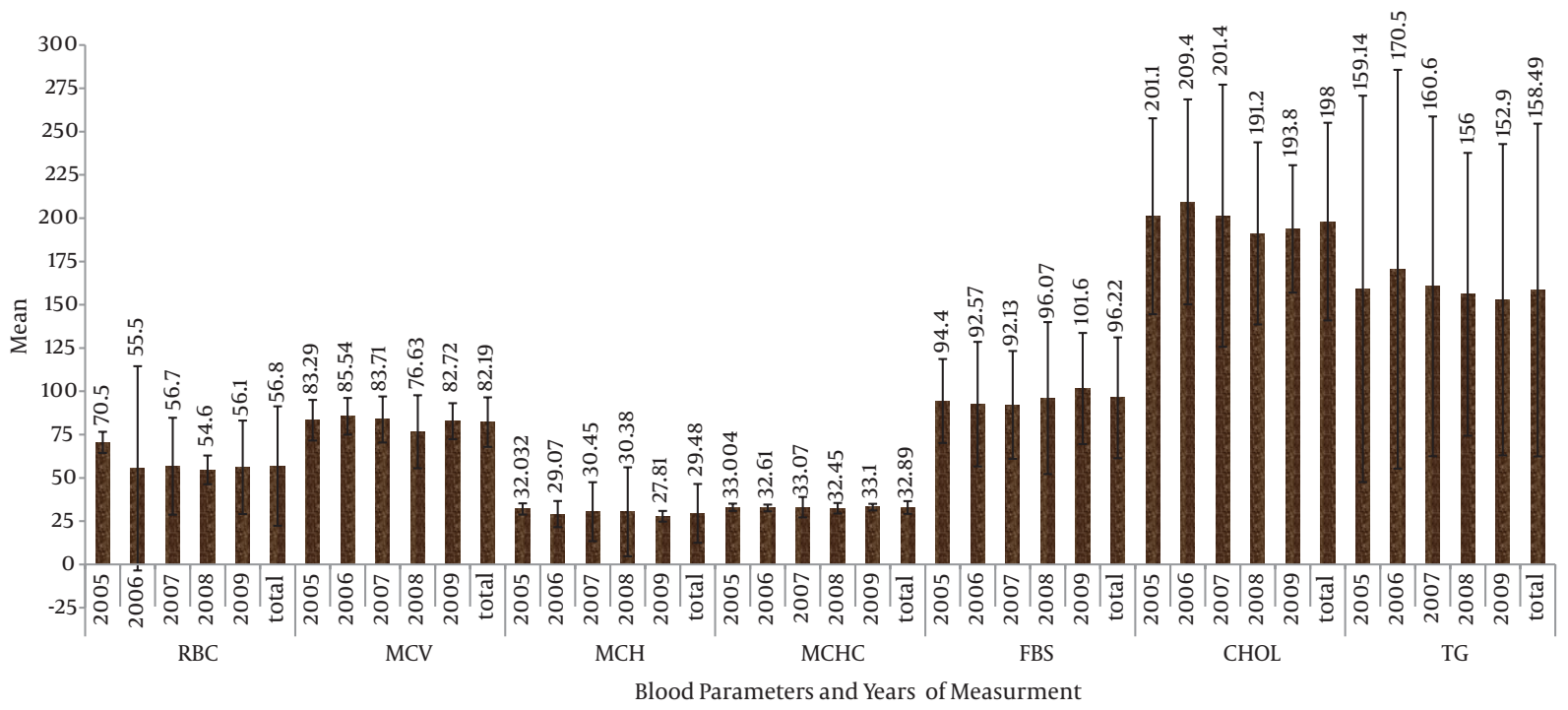

Figure 1. The Trend of Means and Standard Deviations of Some Blood Parameters in Zahedan Drivers From 2005 to 2009

duce or minimize smoking in less experienced drivers. According to the present study results, smoking was more frequent in taxi drivers, compared to other drivers, and they seem to be more mentally preoccupied than other drivers.

In addition, non-smoking drivers had more favorable blood parameters such as blood sugar, and cholesterol. The previous studies $(14,15)$ showed that some blood parameters such as sugar, cholesterol and triglyceride were related to smoking in drivers, which agrees with the present study results. According to the present study results, periodic measurement of blood parameters, especially in smoking drivers is recommended, and they should be informed about test results and damages caused by smoking.

The trend of drivers' blood parameters over five years showed no significant increase in the means of blood parameters. Accordingly, increasing age and work stress have not changed blood parameters, and it is smoking that provides an explanation for these differences over the years. Furthermore, since these data are presented as an overall mean, they cannot show changes in different groups.

In the current study, synergistic effects of underlying variables and smoking, in relation to blood parameters showed an increase in the most important blood parameters (fasting blood sugar, cholesterol, and triglyceride) due to interaction between smoking and age, which indicates the importance of non-smoking in older age that may be due to the collective effects of smoking and other influential factors and age.

\subsection{Conclusions}

Finding low prevalence of drug use among drivers (even according to laboratory techniques), and also low level of smoking according to self-report, neither selfreport nor ordinary laboratory techniques can show correct estimates of smoking in drivers. Thus, it seems that random selection of drivers and random blood sampling at motorway police stops or other centers, without prior knowledge of drivers, and also use of more accurate and sensitive laboratory methods, may be an appropriate method to measure the level of drug use in drivers.

Given adverse effects of smoking on health and driving, it is essential to provide education to reduce smoking and smoking during driving. As the interventions targeting adolescents' smoking habits might benefit from using health education models such as the theory of planned behavior (TPB) model (21), then education based on the model could be more effective to stop smoking in different occupational groups such as drivers. Considering the synergistic effects of age and smoking on abnormal increase in blood parameters, it seems that the effect of smoking is greater in older age, and this should be considered when informing drivers and the general public.

\section{Acknowledgments}

Authors sincerely thank all participants in this study and all individuals for their cooperation in data collection. 


\section{Footnotes}

Authors' Contribution: Alireza Ansari-Moghaddam and Hossein Ansari designed the study and prepared the paper. Mahdi Mohammadi and Seyed Mehdi Tabatabaei contributed to data analysis. Mohammadreza PishevareMofrad and Mahmodreza Miri-Bonjar contributed to data collection. All authors contributed to writing the paper, reading and approving the final draft of the paper.

Funding/Support: This work was approved and funded by the Zahedan University of Medical Sciences.

\section{References}

1. Mehmandar M, Soori H, Amiri M, Norouzirad R, Khabzkhoob M Risk factors for fatal and nonfatal road crashes in iran. Iran Red Crescent Med J. 2014;16(8):e10016. doi: 10.5812/ircmj.10016. [PubMed: 25389468].

2. WHO . Global health risks mortality and burden of disease attributable to selected major risks.; 2009.

3. Cybulski M, Strzelecki W, Grzymislawska-Cybulska M, Glowacka MD, Mojs E. [Determinants of personality and risky road behaviors at work in drivers of medical transport vehicles in the Wielkopolska (Greater Poland) voivodeship]. Med Pr. 2014;65(4):485-96. [PubMed: 25643487].

4. Ozkan T, Lajunen T, Summala H. Driver Behaviour Questionnaire: a follow-up study. Accid Anal Prev. 2006;38(2):386-95. doi: 10.1016/j.aap.2005.10.012. [PubMed: 16310749].

5. Assari S, Moghani Lankarani M, Dejman M, Farnia M, Alasvand R, Sehat $\mathrm{M}$, et al. Drug Use among Iranian Drivers Involved in Fatal Car Accidents. Front Psychiatry. 2014;5:69. doi: 10.3389/fpsyt.2014.00069. [PubMed: 25221521].

6. Borowsky A, Shinar D, Oron-Gilad T. Age, skill, and hazard perception in driving. Accid Anal Prev. 2010;42(4):1240-9. doi: 10.1016/j.aap.2010.02.001. [PubMed: 20441838].

7. Clarke DD, Ward P, Bartle C, Truman W. Older drivers' road traffic crashes in the UK. Accid Anal Prev. 2010;42(4):1018-24. doi: 10.1016/j.aap.2009.12.005. [PubMed: 20441808].

8. Duke J, Guest M, Boggess M. Age-related safety in professional heavy vehicle drivers: a literature review. Accid Anal Prev. 2010;42(2):364-71. doi: 10.1016/j.aap.2009.09.026. [PubMed: 20159055].
9. Jayatilleke AU, Nakahara S, Dharmaratne SD, Jayatilleke AC, Poudel KC, Jimba M. Working conditions of bus drivers in the private sector and bus crashes in Kandy district, Sri Lanka: a case-control study. Inj Prev. 2009;15(2):80-6. doi: 10.1136/ip.2008.018937. [PubMed: 19346419].

10. Lacho L, Kokavec M. [Caffeine and smoking-induced changes in the behavior of car drivers]. J Ev Purkyne. 1979;25(2):22-7.

11. Ryb GE, Dischinger P, Kufera J, Soderstrom C. Smoking is a marker of risky behaviors independent of substance abuse in injured drivers. Traffic Inj Prev. 2007;8(3):248-52. doi: 10.1080/15389580701272353. [PubMed: 17710714]

12. Hansen J, Raaschou-Nielsen O, Olsen JH. Increased risk of lung cancer among different types of professional drivers in Denmark. Occup Environ Med. 1998;55(2):115-8. [PubMed: 9614396].

13. Lam TH, Jiang CQ, Ho SY, Zhang WS, Liu WW, He JM. Smoking and mortality in 81,344 drivers in Guangzhou, China. Occup Environ Med. 2002;59(2):135-8. [PubMed: 11850558].

14. Mohebbi I, Saadat S, Aghassi M, Shekari M, Matinkhah M, Sehat S. Prevalence of metabolic syndrome in Iranian professional drivers: results from a population based study of 12,138 men. PLoS One. 2012;7(2):e31790. doi: 10.1371/journal.pone.0031790. [PubMed: 22384075].

15. Saberi HR, Moravveji AR, Fakharian E, Kashani MM, Dehdashti AR. Prevalence of metabolic syndrome in bus and truck drivers in Kashan, Iran. Diabetol Metab Syndr. 2011;3(1):8. doi: 10.1186/1758-59963-8. [PubMed: 21595922].

16. Motevalian SA, Jahani M, Mahmoodi M. Driving under influence of opiates in heavy vehicle drivers of Iran in 2001. Hakim Res J. 2004;7(1):1-8.

17. Ansari-Moghaddam A, Habybabady RH, Shakiba M, Mirzaei R, Shahriyari F, Aghaei S. Predictors of initiation, continuation and transition of drug use in south-eastern Iran.J Pak Med Assoc. 2012;62(7):698-703. [PubMed: 23866519].

18. Hendricks PS, Peters EN, Thorne CB, Delucchi KL, Hall SM. Expectancies for smoking cessation among drug-involved smokers: implications for clinical practice. J Subst Abuse Treat. 2014;46(3):320-4. doi: 10.1016/j.jsat.2013.10.011. [PubMed: 24314605].

19. Kazemi TSM, Salehi A. Assessment of risk factors of Heart diseases among heavy vehicle drivers in southeastern Iran. J Birjand Univ Med Sci. 2012;19(6):26-32.

20. Mohammadpoorasl A, Ghahramanloo A, Allahverdipour H. RiskTaking Behaviors and Subgrouping of College Students A Latent Class Analysis. Am J Men's Health. 2013;15(5):79-88.

21. Karimy M, Niknami S, Heidarnia AR, Hajizadeh I, Montazeri A. Prevalence and determinants of male adolescents' smoking in iran: an explanation based on the theory of planned behavior. Iran Red Crescent Med J. 2013;15(3):187-93. doi: 10.5812/ircmj.3378. [PubMed: 23983996]. 